This document was prepared in conjunction with work accomplished under Contract No. DE-AC09-96SR18500 with the U.S. Department of Energy.

This work was prepared under an agreement with and funded by the U.S. Government. Neither the U. S. Government or its employees, nor any of its contractors, subcontractors or their employees, makes any express or implied: 1 . warranty or assumes any legal liability for the accuracy, completeness, or for the use or results of such use of any information, product, or process disclosed; or 2 . representation that such use or results of such use would not infringe privately owned rights; or 3 . endorsement or recommendation of any specifically identified commercial product, process, or service. Any views and opinions of authors expressed in this work do not necessarily state or reflect those of the United States Government, or its contractors, or subcontractors. 


\title{
Direct measurement of heat flux from cooling lake thermal imagery
}

\author{
Alfred J. Garrett, Eliel Villa-Aleman, Robert J. Kurzeja, \\ Malcolm M. Pendergast \\ Savannah River National Laboratory, Highway 1, Aiken, SC, USA 29808
}

\begin{abstract}
Laboratory experiments show a linear relationship between the total heat flux from a water surface to air and the standard deviation of the surface temperature field, $\sigma$, derived from thermal images of the water surface over a range of heat fluxes from 400 to $1800 \mathrm{Wm}^{-2}$. Thermal imagery and surface data were collected at two power plant cooling lakes to determine if the laboratory relationship between heat flux and $\sigma$ exists in large heated bodies of water. The heat fluxes computed from the cooling lake data range from 200 to $1400 \mathrm{Wm}^{-2}$. The linear relationship between $\sigma$ and Q is evident in the cooling lake data, but it is necessary to apply band pass filtering to the thermal imagery to remove camera artifacts and non-convective thermal gradients. The correlation between $\sigma$ and $\mathrm{Q}$ is improved if a correction to the measured $\sigma$ is made that accounts for wind speed effects on the thermal convection. Based on more than a thousand cooling lake images, the correlation coefficients between $\sigma$ and $\mathrm{Q}$ ranged from about 0.8 to 0.9 .
\end{abstract}

Keywords: thermal imagery, surface heat flux, cooling lake, buoyant convection, wind stress

\section{INTRODUCTION}

Conover and Saylor [1] have shown in a series of laboratory thermal convection experiments that the heat flux from a heated tank of water to the air above is linearly proportional to the standard deviation of temperature fluctuations at the surface of the fluid, as recorded by an infrared (IR) camera (3.4 to $5 \mu \mathrm{m}$ wavelength sensitivity range). The experimental apparatus consists of a $1 \mathrm{~m}$ long, $0.25 \mathrm{~m}$ wide and $0.38 \mathrm{~m}$ deep water tank with a small wind tunnel above that allows controlled rates of air flow to be forced over the water surface. An IR camera is mounted above the wind tunnel and views the water surface through a hole in the wind tunnel roof. Conover and Saylor [1] conducted a series of experiments in which the heat flux was varied from 400 to $1800 \mathrm{Wm}^{-2}$ and the imposed wind speed over the water surface was varied from zero to $4 \mathrm{~m} / \mathrm{s}$. Conover and Saylor [1] have also explored the effects of surfactants on the surface signatures of the thermal convection under zero wind speed conditions. Naturally occurring or artificial surfactants cover the surface of the water with a thin layer of organic material that retards evaporation and heat transfer and which tends to smooth out the smaller-scale convective structures. The effects of a man-made surfactant (oleyl alcohol) on thermal convection are illustrated in figure (1), which shows IR images taken when the heat flux was 407 $\mathrm{W} / \mathrm{m}^{2}$. It can be seen that the fine scale structure in the case when no surfactant was present on the water surface was gone when the oleyl alcohol was applied.

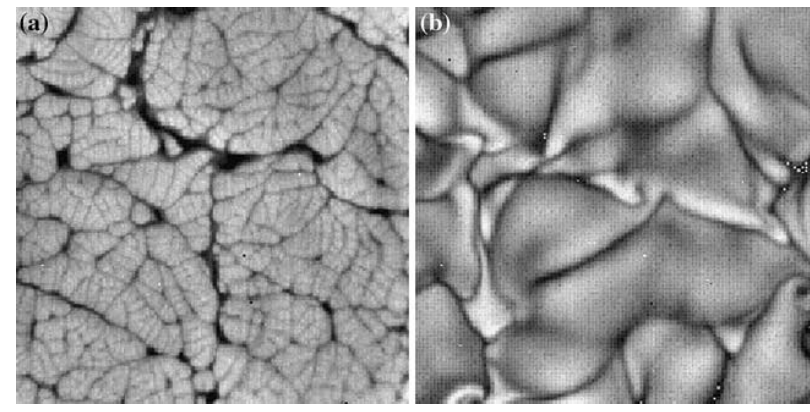

Fig. 1. Comparison of thermal convection patterns from two of Conover and Saylor's laboratory experiments: a) clean water surface and b) water surface covered by a thin layer of oleyl alcohol. Surface heat flux was $407 \mathrm{~W} / \mathrm{m}^{2}$ in both cases. Warm regions are white and cooler regions are dark. For both images the wind speed is zero. Images taken from ref. [1].

Send correspondence to Alfred Garrett: e-mail: alfred.garrett@,srnl.doe.gov, telephone: 803-725-4870 
There was no imposed wind speed over the water in the experiments illustrated in figure (1). Figure (2) presents results from a series of experiments in which forced air flow of $4 \mathrm{~m} / \mathrm{s}$ existed over the water surface, at a heat flux on the order of $600 \mathrm{~W} / \mathrm{m}^{2}$. It can be seen that the air flow elongated the convective cells. The scale in the clean image is about half that of the oleyl alcohol image. Hence the structures are smaller for the clean surface case. The qualitative nature of the structures appears different for the two images as well.
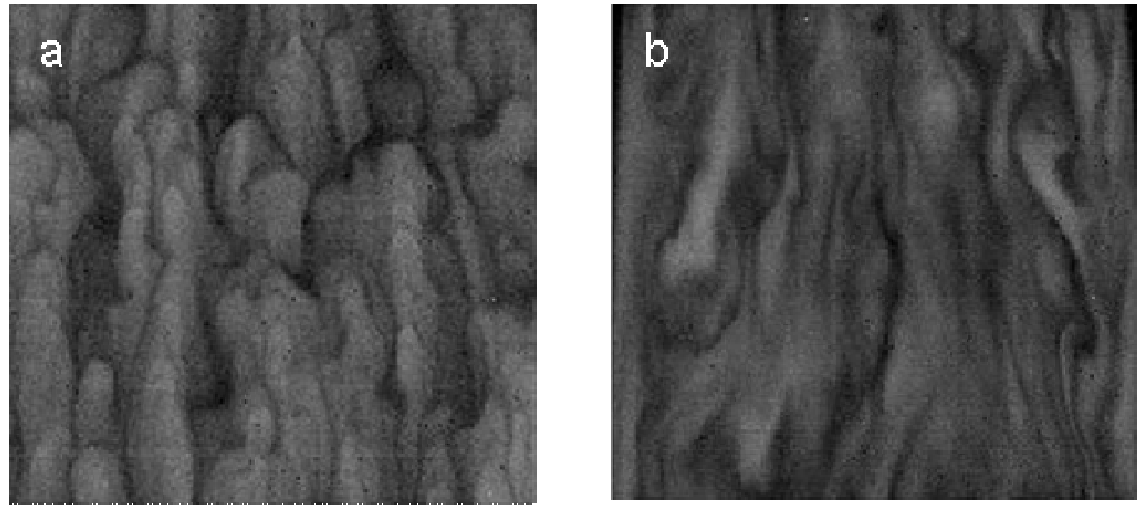

Fig. 2. Comparison of thermal convection patterns from two of Conover and Saylor's laboratory experiments with imposed $4 \mathrm{~m} / \mathrm{s}$ wind speed: a) clean water surface and b) water surface covered by a thin layer of oleyl alcohol. Surface heat flux was $697 \mathrm{~W} / \mathrm{m}^{2}$ for clean case and $576 \mathrm{~W} / \mathrm{m}^{2}$ for oleyl alcohol case. Warm regions are white and cooler regions are dark. Images taken from ref. [1]

In figure (3), data similar to that of Conover and Saylor [1] is presented, over a larger range of wind speeds. This series of experiments was performed to develop a quantitative relationship between the heat flux (Q) and the standard deviation of temperature fluctuations in the thermal images $(\sigma)$, and to determine what impact wind had on this $\sigma-\mathrm{Q}$ relationship. Figure (3) presents the experimental results, separated into wind speed classes of zero to $4 \mathrm{~m} / \mathrm{s}$.

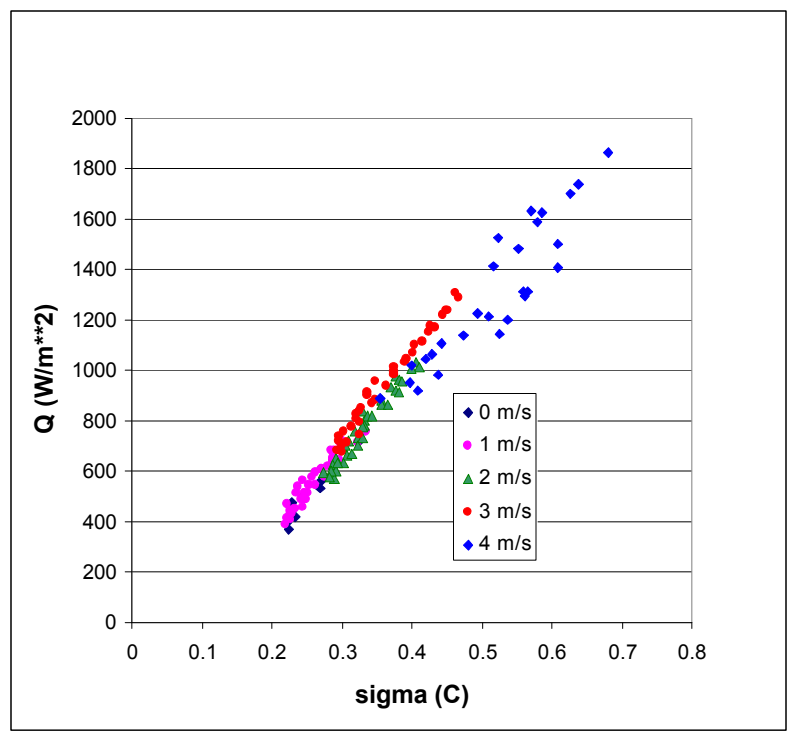

Fig. 3. Relationship between standard deviation of surface temperature fluctuations (sigma) and heat flux (Q) from laboratory experiments. Data are color-coded according to speed of airflow above water surface.

It can be seen that in general there is a linear relationship between $\sigma$ and $\mathrm{Q}$, and that this holds true for all wind speeds investigated. However, it can also be seen that there are small offsets between some of the different wind speed classes. 
The purpose of the research project reported on in this paper is to determine if the laboratory results summarized above apply to much larger bodies of water that are losing thermal energy to the atmosphere via evaporation, sensible heat transfer and thermal radiation losses. If this hypothesis is correct, then it would be possible to quickly and easily determine how much energy is being lost by natural bodies of water such as lakes and oceans in the fall and winter. It would also make it easier to determine how efficiently man-made energy dissipation systems such as power plant cooling lakes are performing. In order to test this hypothesis, the Savannah River National Laboratory (SRNL) collected thermal imagery at two power plant cooling lakes, along with the surface data necessary to compute the surface heat flux at locations on the lake where thermal imagery was collected.

In the following sections the imagery and surface data collections will be first be described, then the methods used to process the imagery and finally the analytical results and conclusions.

\section{COOLING LAKE DATA COLLECTIONS}

SRNL collected thermal imagery and surface data at the H. B. Robinson power plant, located near Florence, South Carolina, and at the Comanche Peak power plant, located near Fort Worth, Texas. The data collections will be described briefly here. A companion paper [2] describes these data collections in greater detail.

The H. B. Robinson power plant is a combined nuclear and fossil-fueled facility that discharges approximately 1800 MW of waste heat into the adjacent lake, which was built specifically for that purpose. Figure (4) is a thermal image of the H. B. Robinson cooling lake taken by the Department of Energy's Multi-spectral Thermal Imager (MTI) satellite.

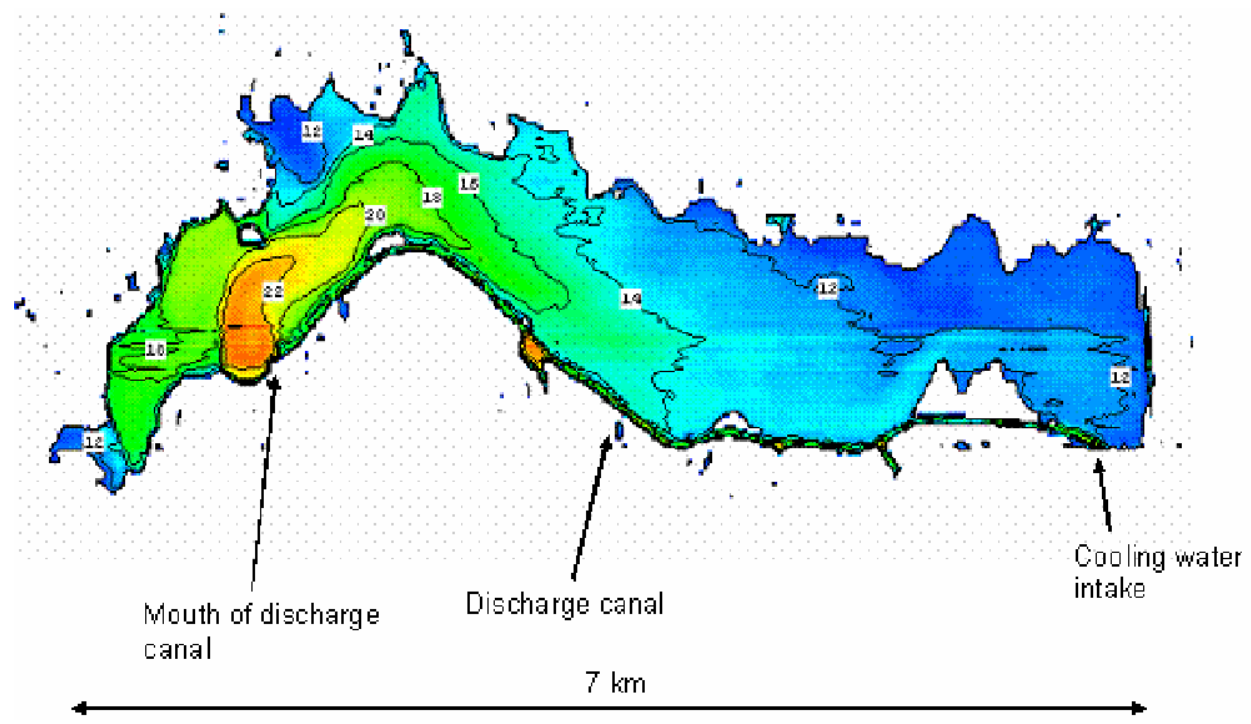

Fig. 4. Multi-spectral Thermal Imager (MTI) image of H. B. Robinson power plant cooling lake. Temperature contours are in ${ }^{\circ} \mathrm{C}$. Power plant is adjacent to cooling water intake. Discharge canal transport heated water from power plant to upper end of lake, where it cools as it returns to the intake.

The area of the lake is $9.2 \mathrm{~km}^{2}$ (2280 acres) and it is long and narrow (approximately $7 \mathrm{~km}$ by $1 \mathrm{~km}$ ). A $6.2 \mathrm{~km} \mathrm{discharge}$ canal carries the heated discharge water from the power plant to the upper end of the lake, where it cools as it slowly flows back to the cooling water intake at the lower end of the lake. The lake is generally shallow, with water depths ranging from 1 to $2 \mathrm{~m}$ in the upper reaches of the lake to about $10 \mathrm{~m}$ at the lower end of the lake near the dam. The heated water that is discharged on the surface of the upper end of the lake spreads as a shallow, hot plume over the cooler water underneath when it reaches deeper water farther away from the end of the discharge canal.

Data collections at H. B. Robinson consisted of two principal components: thermal imagery collections from a helicopter and from a $6 \mathrm{~m}$ mast mounted on a pontoon boat in the lake, and surface data collections needed for computations of the total heat flux leaving the lake (evaporation, sensible heat loss and net loss of thermal radiation). The measured variables 
were air temperature, relative humidity, wind speed and direction and water temperature. Local cloud cover was recorded during the collections. Cloud height and coverage data from local National Weather Service stations were also archived for use in the heat flux calculations. Most of these measurements were made with a floating weather station developed by SRNL and which has been used for a variety of environmental heat flux measurements [3]. The evaporative and sensible heat losses were computed using the relationships described in [4] and the net thermal radiation at the water surface was computed using a simplified 1-D model described in [5]. The methods for computing water surface energy loss rates in [4] and [5] have been used successfully by SRNL in other cooling lake research [6].

The Comanche Peak power plant consists of two 1200 MWe units, and is located about 70 km south of Fort Worth, Texas. It discharges approximately $4500 \mathrm{MW}$ of waste heat into its $13.3 \mathrm{~km}^{2}$ (3270 acre) cooling lake. Figure (5) shows that this cooling lake is about the same length as Lake Robinson $(7.5 \mathrm{~km})$ but is wider, with a width of about $4.5 \mathrm{~km}$ at the lower end. This lake has several side arms that run perpendicular to the main axis of the lake and which are somewhat sheltered from winds blowing along the axis of the lake by low ridges. The sheltering of the side arms from the wind produces conditions in which convective cells in the main body of the lake experience significant wind stress at the same time convective cells in the side arms are developing in calm conditions. It will be shown that the wind stress causes dramatic changes in the structure of the convective cells.

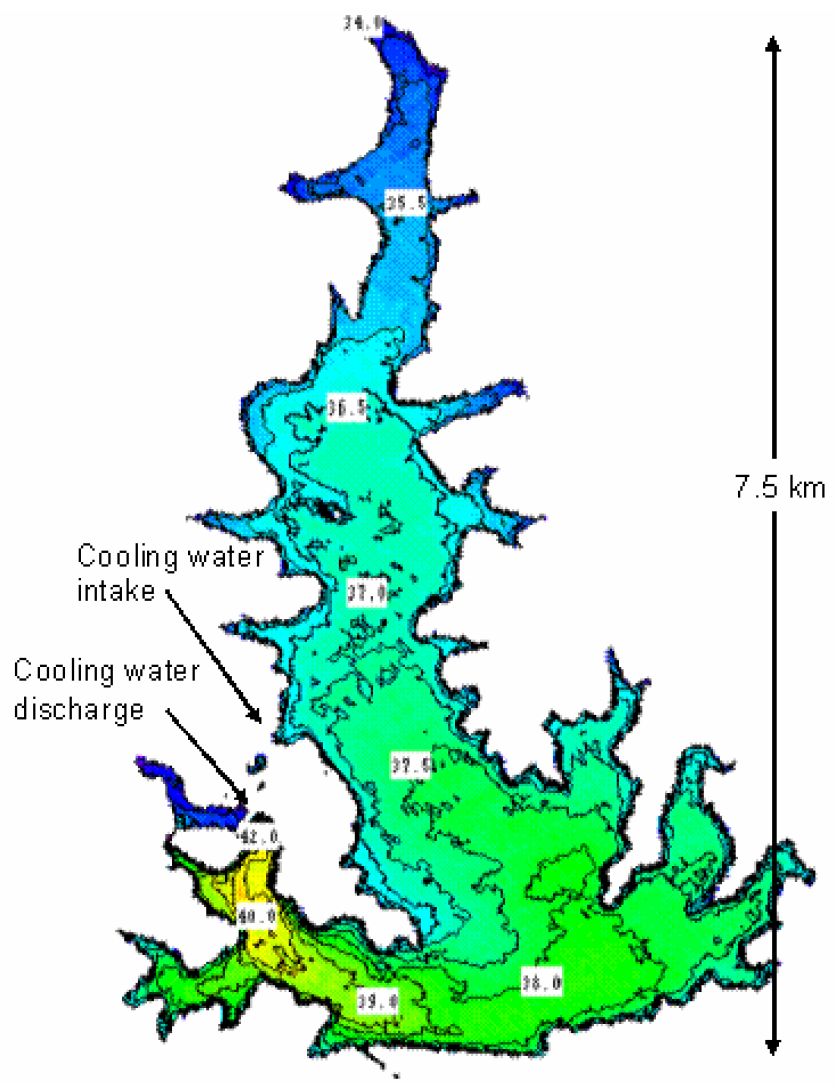

Fig. 5. Multi-spectral Thermal Imager (MTI) image of Comanche Peak power plant cooling lake. Temperature contours are in ${ }^{\circ} \mathrm{C}$. Power plant is between cooling water intake and discharge.

\section{IMAGERY ANALYSIS}

At H. B. Robinson and at Comanche Peak, SRNL collected hundreds of thermal images from helicopters and from a mast on a pontoon boat, along with surface meteorological data and water temperatures. Examination of the thermal imagery taken from the helicopters and from the boat quickly led to the conclusion that much of the thermal variability in the images had nothing to do with buoyancy-driven convection. Some of the extraneous thermal signal was either camera noise or camera artifacts such as the cosine(n) effect. There were also real thermal signals in the imagery unrelated to the 
local buoyancy-generated convective cells; for example, large-scale thermal gradients exist in cooling lakes, particularly along the edges of the discharge plumes. These were removed from the imagery by applying band pass filters that eliminated very short wavelengths no greater than 2 to 3 pixels and wavelengths much longer than the longest convective cell size (usually no more than about 15 pixels). This was implemented using ENVI band pass filter software, as shown in figure (6). It can be seen in figure (6) that the spurious thermal gradients in the image caused by the cosine(n) effect were completely removed by the band pass filter, leaving only the thermal variability caused by the convective cells. SRNL also wrote band pass filter software, which produced essentially the same results as the ENVI software.

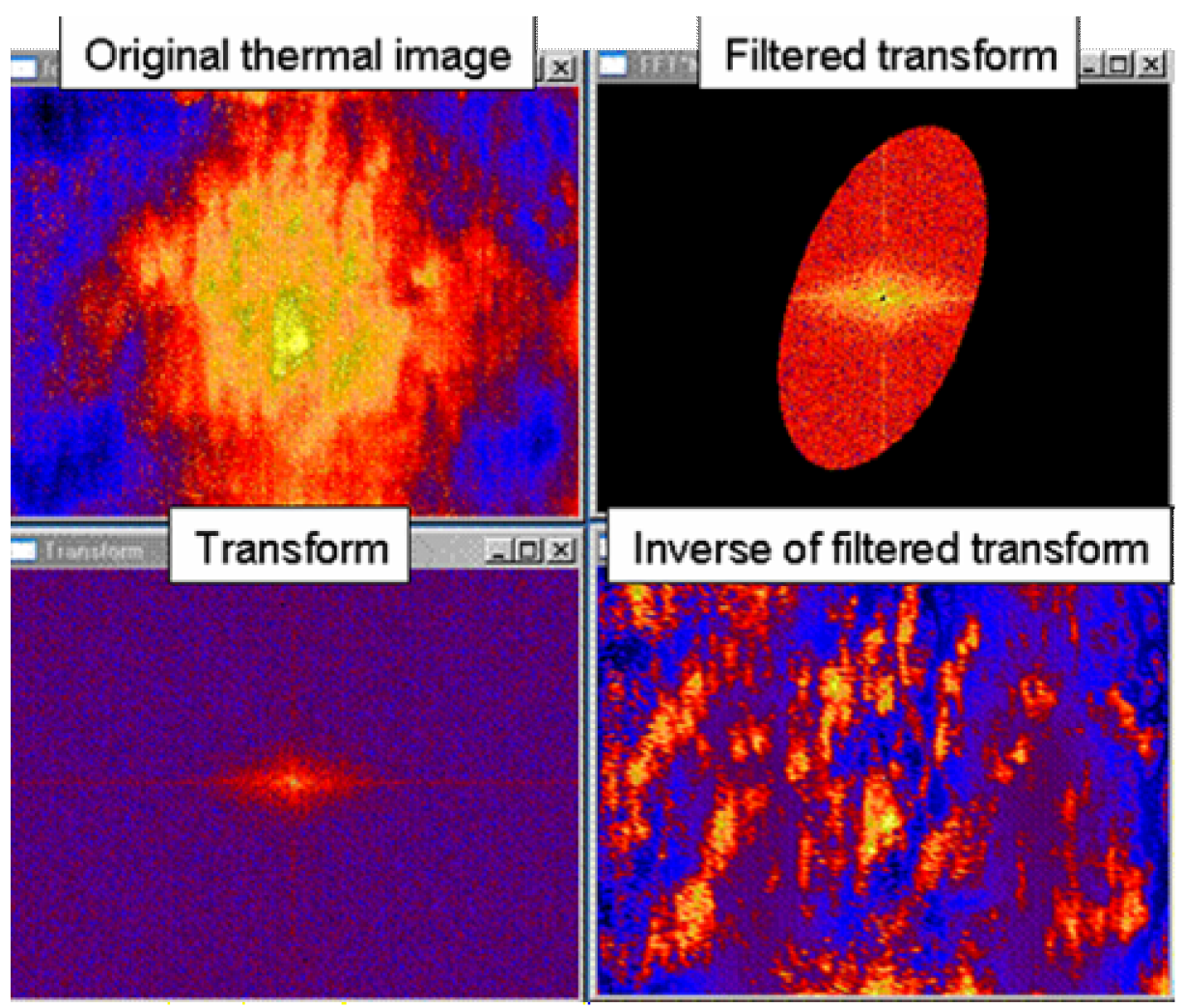

Fig. 6. Band pass filter applied to Lake Robinson thermal image. Band pass filter was applied to remove small scale camera noise, cosine(n) effects and real non-convective thermal variability in the imagery.

Thermal imagery of the cooling lakes at H. B. Robinson and Comanche Peak was collected at a variety of altitudes. The thermal camera on the pontoon boat was about $6 \mathrm{~m}$ above the water surface, whereas the helicopter images were collected at elevations ranging from about $30 \mathrm{~m}$ to several hundred meters. In order to combine the statistical analyses of all these images into a single data base, it was necessary to reference all the images to a single elevation. We chose to reference all of the images to an elevation of $1 \mathrm{~m}$, which is approximately the elevation of the camera above the water surface in the laboratory experiments conducted by Conover and Saylor [1]. The standard deviation $(\sigma)$ of the thermal variability in the images was adjusted to account for the amount of the spectrum of convective scales that was lost as camera resolution decreased with increasing elevation above the water surface. The adjustment was made through use of an empirical equation that was derived to allow images taken at different elevations to be referenced to the same height. This was done by collecting thermal images at one location over Lake Robinson at several elevations, and computing $\sigma$ for each elevation. The assumption in this approach was that $\sigma$ was approximately constant over a limited spatial area and in time over the short period of time that it took to take the images at several elevations. The results of several vertical transects were averaged together to produce the curve shown in figure (7). The best fit to the data in figure (7) is a power law with an exponent of 0.26 : 


$$
\sigma_{R E F}=\sigma_{O B S}\left(\frac{Z_{O B S}}{Z_{R E F}}\right)^{0.26}
$$

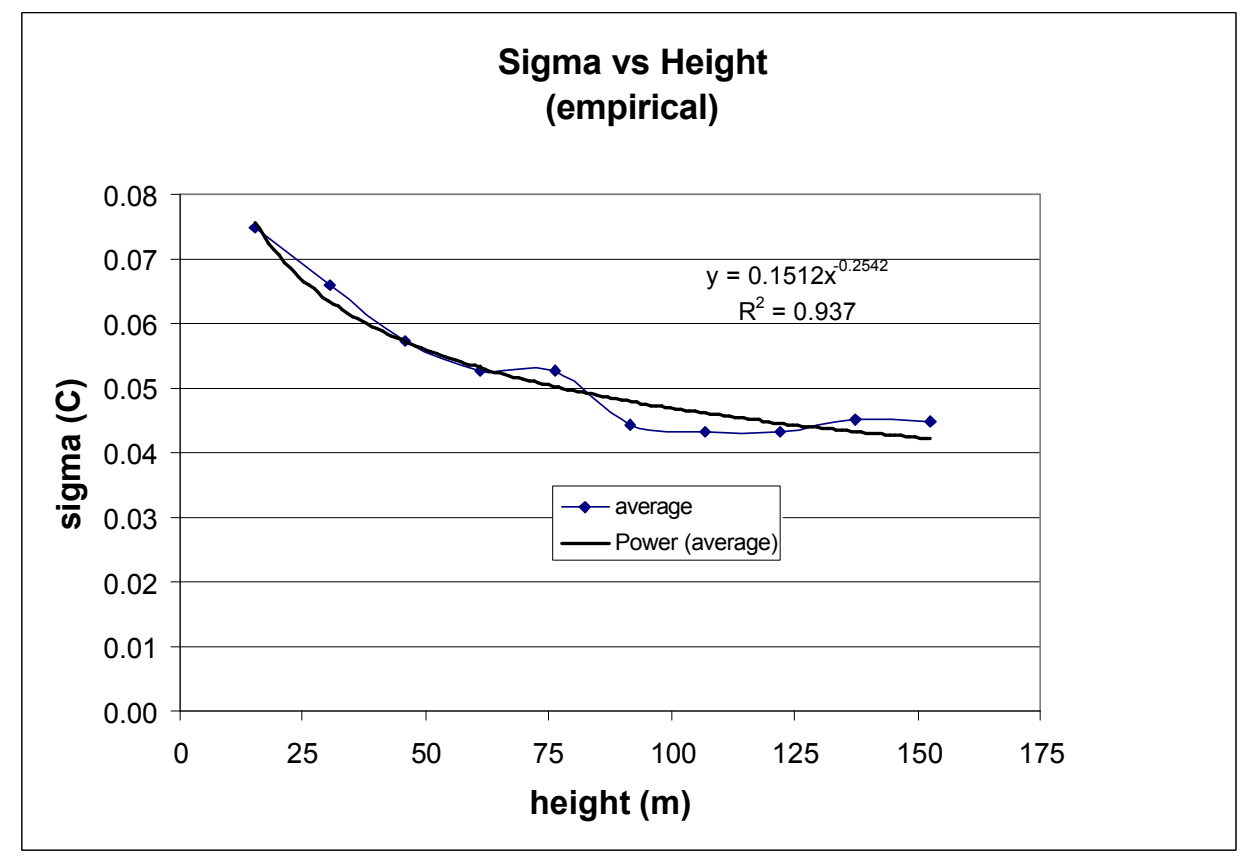

Fig. 7. Relationship between $\sigma$ and height above water surface that image was taken, based on several vertical transects at Lake Robinson.

This power law was used to reference all of the computed $\sigma$ values to the same $1 \mathrm{~m}$ height. This approach could allow the laboratory and cooling lake data to fit on the same curve, and this will be investigated in the future.

Figure (8) shows two thermal images taken a few minutes apart from each other over the Comanche Peak cooling lake. One of the images was taken in the center of the lake which was experiencing winds of 3 to $4 \mathrm{~m} / \mathrm{s}$. The other image was taken over a sheltered side arm of the lake, where there was very little wind. It can be seen that large, irregular convective cells formed in the absence of wind, whereas when significant wind was present, the convective cells were smaller and were oriented in streaks along the direction of the wind. This dramatic effect of wind on the structure and size of the convective cells led to the conclusion that some correction to the computed values of $\sigma$ would produce a better correlation between $\sigma$ and Q. The hypothesis is that this correction would compensate for the upper end of the spectrum of convective cells that cannot exist in the presence of strong mixing caused by turbulence generated by wind shear. The basis for the correction is the assumption that the spectrum of convective cells will shift toward shorter and shorter wavelengths as the ratio of turbulence generated by wind shear increases relative to the turbulence generated by buoyant convection:

$$
\sigma_{C O R}=\sigma_{R E F}\left(1+\frac{p_{W S}}{p_{B F}}\right)
$$


where $\sigma_{\mathrm{COR}}=$ corrected value of $\sigma, \sigma_{\mathrm{REF}}=$ adjusted value of $\sigma$ derived from equation (1), $\mathrm{P}_{\mathrm{ws}}$ is the rate of production of turbulence from wind shear and $\mathrm{P}_{\mathrm{BF}}$ is the rate of production of turbulence from the buoyancy force. Substituting expressions for the two production rates in terms of wind speed and $\sigma$ leads to the following expression:

$$
\sigma_{C O R}=0.5\left(\sigma_{R E F}+\sqrt{\sigma_{R E F}^{2}+0.05 \sigma_{R E F} U^{2}}\right)
$$

In equation (3), $\mathrm{U}$ is wind speed, and the 0.05 coefficient was determined empirically from $\mathrm{H}$. B. Robinson data.
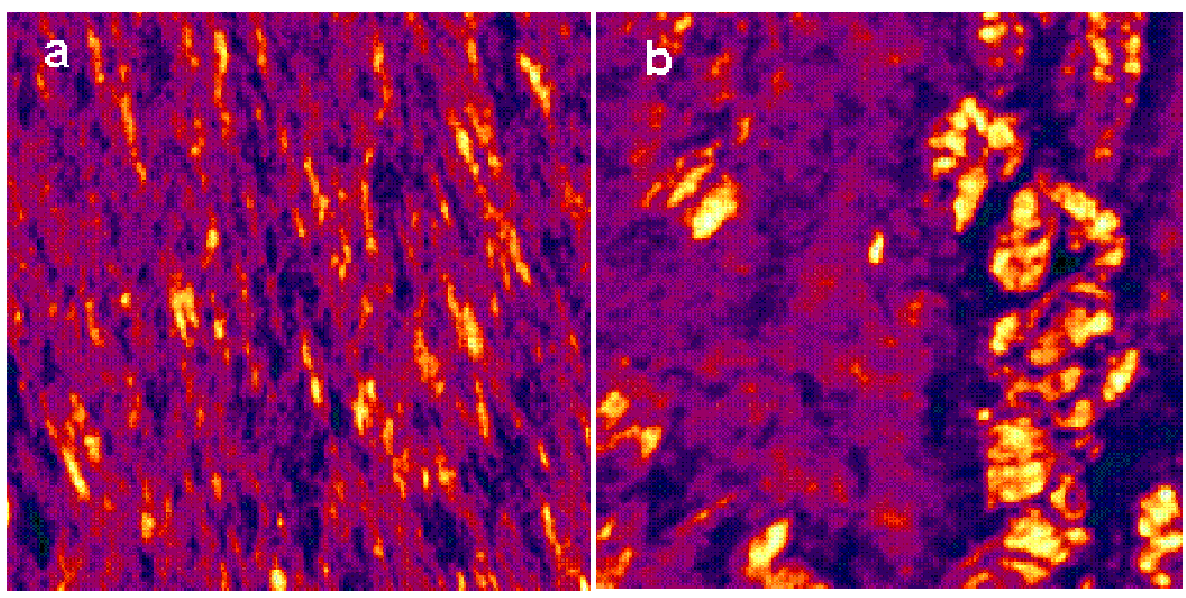

Fig. 8. Two thermal images taken over Comanche Peak power plant cooling lake. Image (a) on left was taken over an area experiencing 3 to $4 \mathrm{~m} / \mathrm{s}$ winds. Image (b) on right was taken in sheltered area in calm conditions.

\section{ANALYTICAL RESULTS}

The thermal imagery collected at H. B. Robinson and Comanche Peak power plants was processed according to the steps listed in the previous section:

- Apply band pass filter to remove thermal variability not related to buoyant convection

- Compute standard deviation of temperature fluctuations $(\sigma)$ in imagery.

- Use equation (1) to adjust $\sigma$ 's derived from images taken at different elevations above water surface to a common reference height of $1 \mathrm{~m}$.

- Use equation (3) to make an additional adjustment to $\sigma$ that accounts for the effects of wind on the size distribution of convective cells.

Figure (9) is shows two Q versus $\sigma$ plots for the 515 images taken from the boat at Lake Robinson. Figure (9a) presents results prior to application of the wind speed correction (equation 3 ), and figure (9b) shows the final $Q$ versus $\sigma$ correlation after application of equation (3). The wind speed correction is significant, raising the $\mathrm{R}^{2}$ value from 0.34 (correlation coefficient $\mathrm{R}=0.58)$ to $0.79(\mathrm{R}=0.89)$. 

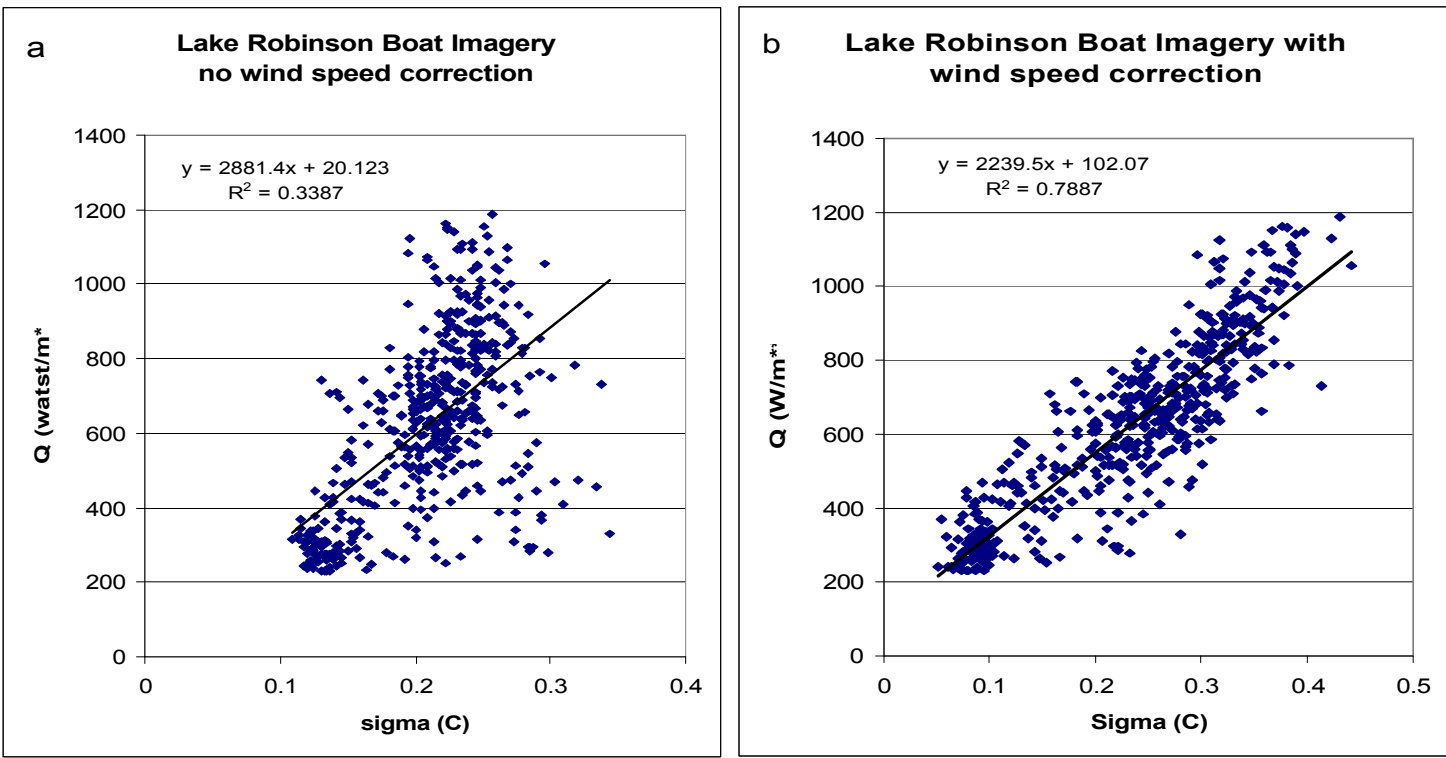

Fig. 9. Heat flux (Q) versus standard deviation of surface temperature $(\sigma)$ relationship derived from 515 thermal images taken from 6 $\mathrm{m}$ mast on a boat in H. B. Robinson power plant cooling lake before (a) and after (b) wind speed correction was applied to $\sigma$.

The remaining scatter in the data shown in figure (9b) can be attributed to a variety of sources. First, there was probably incomplete removal of camera artifacts and large scale thermal gradients in the imagery by the band pass filters. Second, there may be unaccounted effects of variable surfactant coverage on the Q versus $\sigma$ relationship, which may be significant. Third, there are both instrumentation and sampling errors in the meteorological and water temperature data used to compute Q's. Fourth, at wind speeds high enough to produce breaking waves (about $5 \mathrm{~m} / \mathrm{s}$ ), the frothy bubbles generated by the waves create cold spots in the imagery because the bubbles immediately adjust to the ambient wet bulb temperature, which is well below the water temperature in all the cases analyzed here. There has been no attempt yet to remove these cold spots from the imagery. Fifth, when there was significant wind, it was difficult to maintain the orientation of the boat so that the camera imaged an area entirely out of the boat wake. Finally, the data shown in figure (9) were collected over several days in periods lasting 2 to 3 hours at a specific location on one of the lakes. In most cases, 100 to 200 images were taken during each of these collection periods usually at a rate of one per minute. The locations imaged by the thermal camera and the surface data collection locations were within $20 \mathrm{~m}$ of each other, so the spatially-induced errors are probably small. But since the imagery and surface data were collected in the same location, the average water temperature and weather conditions were nearly constant, with individual measurements randomly falling around those averages. A lag on the order of one minute was observed between a change in wind speed and a corresponding adjustment in the appearance of the convective cells, which adds to the scatter in the data.

Figure (10) presents the results from analysis of (a) the Comanche Peak boat imagery and (b) the combined results from both cooling lakes. The exact same methodology was applied to imagery from both lakes. The $\mathrm{R}^{2}$ value of $0.59(\mathrm{R}=$ $0.77)$ is not as high as the Lake Robinson $R^{2}$ of $0.79(R=0.89)$, which can probably be attributed to higher average wind speeds, which would have made the problems associated with breaking waves and boat wake effects more pronounced. The combined $\mathrm{R}^{2}$ of $0.70(\mathrm{R}=0.84)$ is based on more than one thousand images, and clearly shows that the same relationship between $\sigma$ and $\mathrm{Q}$ exists in both cooling lakes, which are different from each other in a variety of ways (geographic location, climate, depth, configuration and heat load). The consistency of the results for the two lakes is also evident from the fact that the slopes of the best fit lines are almost the same. 

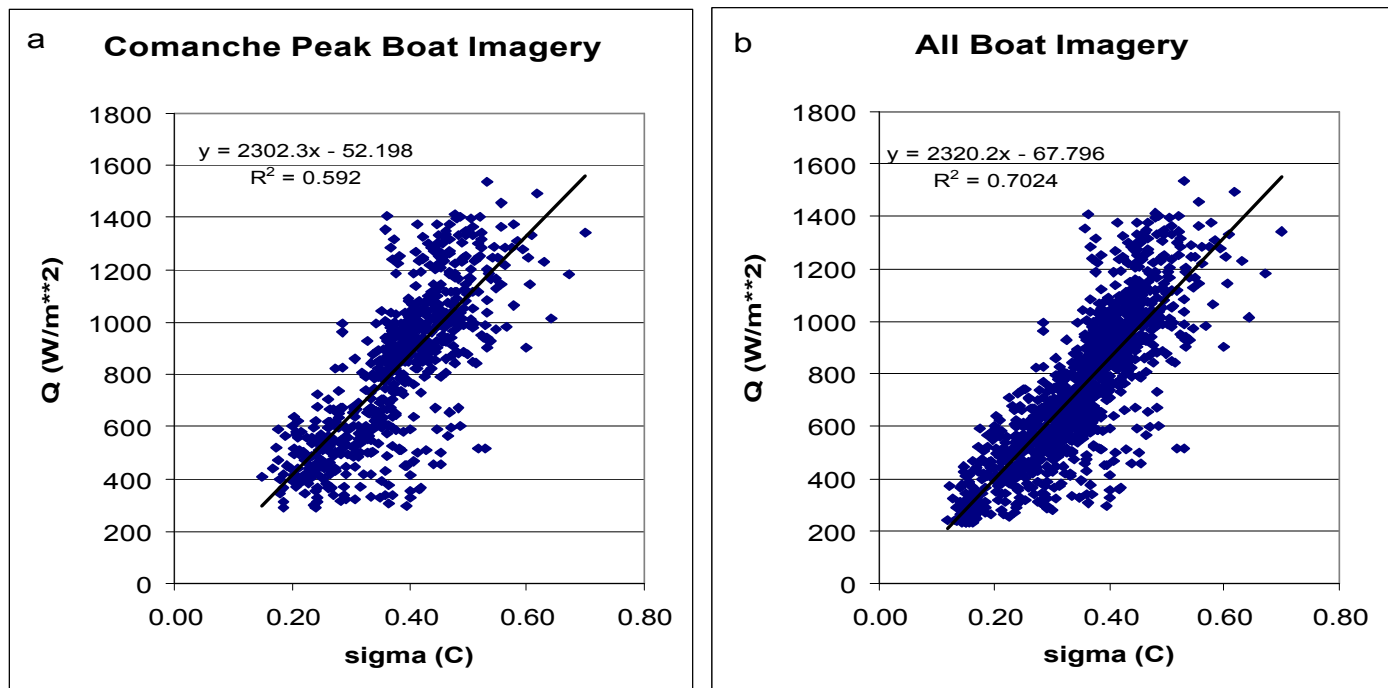

Fig. 10. Standard deviation of temperature fluctuations $(\sigma)$ versus heat flux $(Q)$ relationship (a) derived from 660 thermal images taken from $6 \mathrm{~m}$ mast on a boat in Comanche Peak power plant cooling lake and (b) combined data from H. B. Robinson and Comanche Peak.

\section{CONCLUSIONS AND FUTURE WORK}

The research presented in this paper demonstrates that high resolution thermal imagery can be used to quickly measure the heat flux from bodies of water such as lakes, reservoirs and cooling ponds. The method requires only thermal imagery with sufficient resolution to capture the larger convective cells and wind speed measurements. Band pass filters from readily available commercial software were applied to the imagery. An empirically derived formula was used to correct for variable image resolution that was the result of collecting images at different elevations above the water surface. This approach avoids the necessity to have accurately calibrated thermal imagery, which would be needed if the heat losses were being computed using formulas that estimate evaporation rates. Although this research was conducted at two power plant cooling lakes, it will apply to any body of water that is losing significant amounts of heat to the atmosphere. For example, natural, unheated lakes typically lose heat to the atmosphere at night and after the passage of a cold front. So this methodology could be applied to lakes and the ocean in the fall, when cold fronts pass over water bodies that still retain summer heat.

This paper reported on boat-based imagery collections at the H. B. Robinson and Comanche Peak power plants. SRNL also collected thousands of images from helicopters over both power plant cooling lakes. Initial analysis of the H. B. Robinson helicopter-based imagery shows the same $\sigma-$ Q relationship observed in the cooling lake boat-based imagery. The results of the helicopter imagery analyses will be presented in a future paper. The helicopter imagery analysis will explore the extent to which heat fluxes can be determined when a larger part of the spectrum of convective cells is not resolved in the imagery.

\section{ACKNOWLEDGMENTS}

This report was prepared for the United States Department of Energy under Contract No. DE-AC09-96SR18500. The authors would like to thank the personnel at the H. B. Robinson and Comanche Peak power plants for their support. 


\section{REFERENCES}

1 T. A. Conover and J. R. Saylor. "Statistics of the surface temperature field of an air/water interface under air flow." Experiments in Fluids, 43, 509-524, Oct. 2007.

2 E. Villa-Aleman, A. J. Garrett, M. M. Pendergast, T. B. Brown, S. R. Salaymeh. "Aerial measurements of convection cell elements in heated lakes." SPIE Defense + Security Conference, paper 6939-27, Orlando, March 16-20, 2008.

3 R. J. Kurzeja, M. M. Pendergast and E. Villa-Aleman. "Measurements of skin temperature on small lakes." J. Atmos. \& Ocean. Tech., 22, 1423-1432, Sept. 2005.

4 J. F. Louis. “A parametric model of vertical eddy fluxes in the atmosphere”. Boundary-Layer Meteorology, 17, 187202, 1979.

$5 \quad$ K. Y. Kondratyev. Radiation in the Atmosphere. Academic Press, New York, New York. 1969.

6 A. J. Garrett and D. W. Hayes. "Cooling lake simulations compared to thermal imagery and dye tracers'. J. Hydr. Engrg., 123, 885-894, Oct. 1997. 